Correspondence: Dr Gordon-Larsen, Department of Nutrition, University of North Carolina, 123 W Franklin St, University Square, Chapel Hill, NC 27516 (pglarsen@unc .edu).

Financial Disclosure: None reported.

1. Cummins S, Petticrew M, Sparks L, Findlay A. Large scale food retail interventions and diet. BMJ. 2005:330(7493):683-684

2. Tarnapol Whitacre P, Tsai P, Mulligan J. The Public Health Effects of Food Deserts: Workshop Summary. Washington, DC: Institute of Medicine and National Research Council; 2009.

3. Borradaile KE, Sherman S, Vander Veur SS, et al. Snacking in children: the role of urban corner stores. Pediatrics. 2009;124(5):1293-1298.

4. Lucan SC, Karpyn A, Sherman S. Storing empty calories and chronic disease risk: snack-food products, nutritive content, and manufacturers in Philadelphia corner stores. J Urban Health. 2010;87(3):394-409.

5. The White House, Office of the First Lady. First Lady Michelle Obama announces nationwide commitments to provide millions of people access to healthy, affordable food in underserved communities. http://www.whitehouse .gov/the-press-office/2011/07/20/first-lady-michelle-obama-announces -nationwide-commitments-provide-milli. Accessed October 12, 2011.

\section{What Is Professionalism?}

I $\mathrm{n}$ reading the Special Article in the August 8/22, 2011, issue of the Archives, with the subtitle "Meeting the Responsibility of Professionalism" it appeared to me that this was a subject of quality performance. ${ }^{1}$ As defined in the dictionary, professionalism is the conduct, aims, or qualities that characterize or mark a profession or a professional person. General rules of behavior apply to all professions. In medicine these qualities are particularly compelling because much of our fees involve outside organizations including the federal government. A relevant article was recently published addressing this subject as well as health care reform, of vital interest to both our profession and the public. ${ }^{2}$ This bill has now been passed but is subject to court challenges. In my view, professionalism for a physician means placing the interests of the patient ahead of his or her own interests, including financial interests. Many individual physicians support this bill, but in my opinion medical professional organizations are not enthusiastic about or in support of cost-cutting measures that will affect their income.

\section{Albert J. Finestone, MD, MSc}

Author Affiliation: Associate Dean CME, Emeritus, School of Medicine, Temple University, Philadelphia, Pennsylvania.

Correspondence: Dr Finestone, The Albert J. Finestone Office for Continuing Medical Education, Kresge Science Hall, 3440 N Broad St, Philadelphia, PA 19140 (afinesto@temple.edu).

Financial Disclosure: None reported.

1. Good Stewardship Working Group. The "Top 5" lists in primary care: meeting the responsibility of professionalism. Arch Intern Med. 2011;171(15) $1385-1390$

2. Brody H. Medicine's ethical responsibility for health care reform - the top five list. N Engl J Med. 2010;362(4):283-285.

\section{In reply}

Dr Finestone inquires whether the generation of the "Top 5 " lists by the Good Stewardship working groups is better characterized as a subject of quality performance rather than professionalism. Our characterization of the effort as professionalism arises from the Physician Charter, in which the definition of professionalism rests, in part, on the principle of social justice. The charter ethically commits physicians to work toward "the wise and cost-effective management of limited clinical resources."

The ethical principle of justice requires that everyone be treated fairly. Professionalism requires that resources be used wisely. Both assure that resources are allocated in the fairest and most effective manner. Making wise clinical decisions and being good stewards of clinical resources creates a health system that provides the best care to the most people.

The "Top 5" lists are not merely clinical guidelines but a fundamental appeal to physicians' sense of professional obligation to achieve a sustainable health care system for all Americans. This epitomizes the concept of professionalism.

\section{Stephen R. Smith, MD, MPH \\ for the Good Stewardship Working Group of the National Physicians Alliance}

Author Affiliation: Department of Family Medicine, Brown University, New London, Connecticut.

Correspondence: Dr Smith, Department of Family Medicine, Brown University, 899 Montauk Ave, New London, CT 06320 (Stephen_R_Smith@brown.edu).

Financial Disclosure: None reported.

Group Information: A list of The Good Stewardship Working Group Members was published in Arch Intern Med. 2011;171(15):1385-1390.

1. ABIM Foundation. Medical professionalism in the new millennium: a physician charter. 2002. http://www.abimfoundation.org/Professionalism/ /media /Files/Physician\%20Charter.ashx. Accessed October 5, 2011.

\section{Do Procalcitonin Algorithms Modify Mortality?}

I $\mathrm{n}$ reporting the results of the systematic review "Procalcitonin Algorithms for Antibiotic Therapy Decisions: A Systematic Review of Randomized Controlled Trials and Recommendations for Clinical Algorithms," Schuetz et al ${ }^{1}$ state that measurement of procalcitonin (PCT) levels for antibiotic decisions in patients with respiratory tract infections and sepsis does not worsen the mortality rate. We are doubtful about their conclusions. We believe that the meta-analysis is underpowered to provide evidence that PCT can affect mortality. Mortality was the primary outcome in only 3 of 14 randomized controlled trials included in the study, and in the primary setting studies (approximately 25\% of the subjects) death was an extremely rare event (1 event). A second issue to be addressed is that the metaanalysis involved trials with very different clinical settings (clinical heterogeneity); thus, we wonder if it should be more appropriate to perform a random effect analysis, irrespectively of the statistical significance of the heterogeneity. Finally, regarding the methodological quality of original randomized controlled trials, we ask the authors if the global adherence to the protocols (that was 
low in almost all studies) can be a bias affecting the results of the meta-analysis.

\author{
Laura Ferrari, MD \\ Francesco Casella, MD \\ Gian Marco Podda, MD \\ for the Gruppo di Autoformazione \\ Metodologica (GRAM)
}

Author Affiliations: Medicina III, Ospedale San Paolo (Drs Ferrari and Podda), and Dipartimento di Medicina, Chirurgia e Odontoiatria (Drs Ferrari and Podda), and Unità Operativa di Medicina Interna II, Dipartimento di Scienze Cliniche "L. Sacco," Ospedale L. Sacco (Dr Casella), Università degli Studi di Milano, Milan, Italy.

Correspondence: Dr Podda, Medicina III, Ospedale San Paolo, Dipartimento di Medicina, Chirurgia e Odonotoiatria, Università degli Studi di Milano, Milan, Italy (gmpodda@gmail.com).

Gruppo di Autoformazione Metodologica (GRAM) Group Members: Piergiorgio Duca, MD; Nicola Montano, MD; Simone Birocchi, MS; Giovanni Casazza, PhD; Francesco Casella, MD; Elisa Ceriani, MD; Giulia Cernuschi, MD; Giorgio Costantino, MD; Franca Dipaola, MD; Laura Ferrari, MD; Francesca Gianni, MD; Francesca Perego, MD; Gian Marco Podda, MD; Mariateresa Pugliano, MD; Anna Maria Rusconi, MD; Monica Solbiati, MD; Ludovica Tagliabue, MD.

Financial Disclosure: None reported.

1. Schuetz P, Chiappa V, Briel M, Greenwald JL. Procalcitonin algorithms for antibiotic therapy decisions: a systematic review of randomized controlled trials and recommendations for clinical algorithms. Arch Intern Med. 2011;171 (15):1322-1331.

$$
\text { In reply }
$$

The aims of our review were to summarize results of previous randomized controlled trials investigating the effects of procalcitonin protocols for antibiotic stewardship decisions, with particular focus on the different protocols used, and to propose clinical algorithms for use in future trials. We found that none of the trials reported increased rates of mortality or other adverse outcomes; yet, only 4 of them were noninferiority trials and adequately powered to address mortaility. ${ }^{1-4}$ Mortality was also similar between groups in a pooled analysis using aggregate data of individual trials, but we agree with Ferrari et al that these results should be viewed with caution.

The 95\% confidence interval cannot rule out a clinically relevant increase in mortality in high-risk settings, and other relevant clinical outcomes were not considered for pooled analysis. Although a sensitivity analysis using a random effects model (summary odds ratio for mortality, 0.91; 95\% CI, 0.73-1.15) confirms our previous results with the Peto method, the differences in settings, patient acuity, underlying type of infection, and methodological quality of trials make an aggregate data meta-analysis a suboptimal choice. Therefore, an individual patient data meta-analysis focus- ing on patients with acute respiratory tract infections with a comprehensive list of patient-relevant outcomes, standardized outcome definitions across trials, and predefined sensitivity and subgroup analyses is under way in an attempt to resolve these remaining uncertainties. ${ }^{5}$ Within this analysis we also aim to investigate whether methodological shortcomings, such as the low adherence rates in some of the studies, would influence the interpretation of results.

We also agree that future work is needed to confirm the safety of procalcitonin protocols, particularly in nonEuropean countries and in critical care settings. Toward this aim, we believe that our review provides important and timely information and that the proposed algorithms are a summary of the current state of knowledge in the field. We hope that this may lay ground for future research to tackle the existing vicious cycle of antibiotic overuse and emerging bacterial resistance.

$$
\begin{aligned}
& \text { Philipp Schuetz, MD, MPH } \\
& \text { Matthias Briel, MD, MSc } \\
& \text { Victor Chiappa, MD } \\
& \text { Jeffrey L. Greenwald, MD }
\end{aligned}
$$

Author Affiliations: Department of Emergency, Harvard School of Public Health, Boston, Massachusetts (Dr Schuetz); Department of Clinical Epidemiology and Biostatistics, McMaster University, Hamilton, Ontario, Canada (Dr Briel); and Department of Medicine, Inpatient Clinician Educator Service, Massachusetts General Hospital, Boston (Drs Chiappa and Greenwald). Correspondence: Dr Schuetz, Department of Emergency, Harvard School of Public Health, 667 Huntington Ave, Boston, MA 02115 (philipp.schuetz@post .harvard.edu).

Financial Disclosure: Dr Schuetz receives support from BRAHMS Inc and Biomerieux to attend meetings and fulfill speaking engagements.

Funding/Support: Dr Schuetz was supported by a research grant from the Swiss Foundation for Grants in Biology and Medicine (Schweizerische Stiftung für medizinisch-biologische Stipendien, SSMBS, PASMP3-127684/1). Dr Briel is supported by grants from Santésuisse and the Gottfried and Julia BangerterRhyner Foundation.

1. Briel M, Schuetz P, Mueller B, et al. Procalcitonin-guided antibiotic use vs a standard approach for acute respiratory tract infections in primary care. Arch Intern Med. 2008;168(18):2000-2007.

2. Burkhardt $\mathrm{O}$, Ewig $\mathrm{S}$, Haagen $\mathrm{U}$, et al. Procalcitonin guidance and reduction of antibiotic use in acute respiratory tract infection. Eur Respir J. 2010;36 (3):601-607.

3. Schuetz P, Christ-Crain M, Thomann R, et al; ProHOSP Study Group. Effect of procalcitonin-based guidelines vs standard guidelines on antibiotic use in lower respiratory tract infections: the ProHOSP randomized controlled trial. JAMA. 2009;302(10):1059-1066.

4. Bouadma L, Luyt CE, Tubach F, et al; PRORATA trial group. Use of procalcitonin to reduce patients' exposure to antibiotics in intensive care units (PRORATA trial): a multicentre randomised controlled trial. Lancet. 2010;375 (9713):463-474

5. Schuetz P, Briel M, Christ-Crain M, et al. Procalcitonin to initiate or withhold antibiotics in acute respiratory tract infections (Protocol). Cochrane Database Syst Rev. 2008;(4):CD007498. 